\title{
LEFT ZEROID AND RIGHT ZEROID ELEMENTS OF $\Gamma$-SEMIRINGS
}

\author{
M. Murali Krishna RaO \\ AND \\ K.R. KUMAR \\ Department of Mathematics \\ GITAM University, Visakhapatnam, 530 045, India \\ e-mail: mmarapureddy@gmail.com \\ rkkona72@rediffmail.com
}

\begin{abstract}
In this paper we introduce the notion of a left zeroid and a right zeroid of $\Gamma$-semirings. We prove that, a left zeroid of a simple $\Gamma$-semiring $\mathrm{M}$ is regular if and only if $\mathrm{M}$ is a regular $\Gamma$-semiring.

Keywords: left zeroid, right zeroid, idempotent, $\Gamma$-semiring, division $\Gamma$ semiring.
\end{abstract}

2010 Mathematics Subject Classification: 16Y60, 03G25.

\section{REFERENCES}

[1] P.J. Allen, A fundamental theorem of homomorphism for semirings, Proc. Amer. Math. Soc. 21 (1969) 412-416. doi:10.1090/S0002-9939-1969-0237575-4

[2] S. Bourne and H. Zassenhaus, On the semiradical of a semiring, Proceedings N.A of S of USA 44 (1958) 907-914.

[3] A.H. Clifford and D.D. Miller, Semigroups having zeroid elements, Amer. J. Math. 70 (1948) 117-125. doi:10.1090/S0002-9904-1955-09895-1

[4] D.F. Dawson, Semigroups having left or right zeroid elements, Bolyai. Institute University of Szeged (1965) 93-96.

[5] H. Lehmer, A ternary analogue of abelian groups, Amer. J. Math. 59 (1932) 329-338. doi:10.2307/2370997 
[6] W.G. Lister, Ternary rings, Trans. Amer. Math. Soc. 154 (1971) 37-55. doi:10.2307/1995425

[7] M. Murali Krishna Rao, $\Gamma$-semirings-I, Southeast Asian Bulletin of Mathematics 19 (1995) 49-54.

[8] M. Murali Krishna Rao, Г-semirings-II, Southeast Asian Bulletin of Mathematics 21 (1997) 281-287.

[9] M. Murali Krishna Rao, The Jacobson radical of $\Gamma$-semiring, Southeast Asian Bulletin of Mathematics 23 (1999) 127-134.

[10] M. Murali Krishna Rao and B. Venkateswarlu, Regular $\Gamma$-semiring and field $\Gamma$ semiring, Novi Sad J. Math. 45 (2015) 155-171.

[11] M.K. Sen, On Г-semigroup, Proc. of International Conference of Algebra and its Application (Decker Publicaiton, New York, 1981) 301-308.

[12] V. Neumann, On regular rings, Proc. Nat. Acad. Sci. 22 (1936) 707-713. doi:org/10.1073/pnas.22.12.707

[13] N. Nobusawa, On a generalization of the ring theory, Osaka J. Math. 1 (1964) 81-89. ir.library.osaka-u.ac.jp/dspace/bitstream/11094/12354/1/ojm 01-01-08.pdf

[14] H.S. Vandiver, Note on a simple type of algebra in which the cancellation law of addition does not hold, Bull. Amer. Math. 40 (1934) 914-921. doi:10.1090/s0002-9904-1934-06003-8

Received 4 March 2017

Revised 13 April 20177

Accepted 24 April 2017 